\title{
J
}

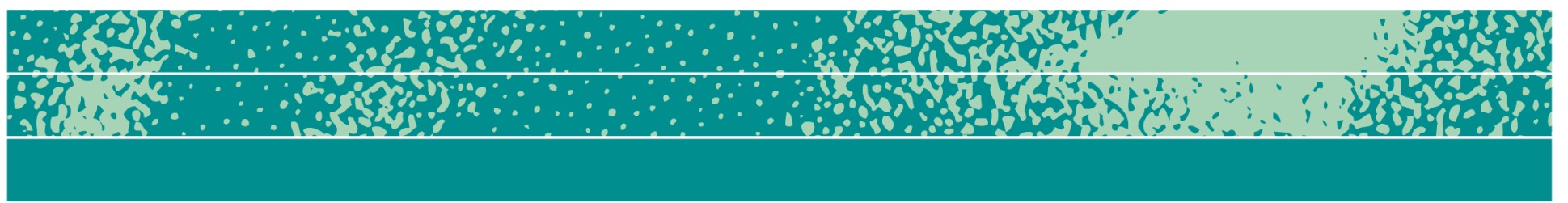

\section{Critique as Collaboration in Design Anthropology}

\author{
Laura Forlano and Stephanie Smith
}

\begin{abstract}
Design anthropology is an emerging field at the intersection of design and anthropology with a distinct style of knowing. This paper argues that in order to create transdisciplinary practices around collaboration for design anthropology, the field must understand existing practices of critique in the field of design. Based on a two-year National Science Foundation funded study of collaboration with designers and design educators in four countries, this article describes the culture of critique that underpins the collaborative practices of designers. In particular, designers often participate in a studio-based culture of critique, which is learned in art and design schools, even when it is not explicitly taught. Finally, as the field of design anthropology matures to include global networks of scholars and practitioners, it is useful to consider the ways in which emergent practices of critique as collaboration, supported by digital platforms, might move beyond the design studio and into distributed collaborations.
\end{abstract}

Keywords critique, collaboration, design, anthropology, distributed
Page 1 of 22

JBA 7(2): 279-300

Autumn 2018

(C) The Author(s) 2018

ISSN 2245-4217

www.cbs.dk/jba 


\section{Introduction}

Design anthropology is a transdisciplinary field that incorporates theories, methods and practices from the field of design and anthropology. One approach that has not yet been discussed in detail is studio-based culture of critique in the design field, which differs significantly from the practice of peer review in the social sciences, and, specifically in anthropology. Based on a two-year National Science Foundation funded study of collaboration with designers and design educators in four countries, this paper seeks to map the practices of critique in the design field, which are often learned in art or design school. Finally, this paper argues that in order to develop trandisciplinary practices of critique for the field of design anthropology, it is necessary to move beyond the design studio model. Specifically, in order to cultivate global research communities in design anthropology like those in other scientific disciplines, a distributed approach to critique as collaboration, enabled by digital platforms, is essential.

Design anthropology is a heterogenous field that draws on the strengths of both design and anthropology. While design is futureoriented, action-oriented and making-oriented, anthropology is typically concerned with using ethnography to describe, document and make sense of the rituals, processes and lived experiences of people and the ways in which they understand their everyday lives. According to Wendy Gunn, Ton Otto and Rachel Charlotte Smith, design anthropology offers the opportunity to change the relationship between theory and practice and to develop critical practices of "collaborative future making" (2013). In particular, they echo discussions around practice-based design research (Agre, 1997; Buchanan, 2001; Ratto, 2011; Redström, 2017; Wakkary, Odom, Hauser, Hertz, \& Lin, 2015; Zimmerman, Forlizzi, \& Evenson, 2007) by asking whether it is possible to draw on practice in order to develop theory.

We argue that the social practices (Pickering, 1995; Reckwitz, 2002; Shove, Pantzar, \& Watson, 2012) embedded within the studiobased design critique offer opportunities for action, intervention and reflection (Schön, 1983) throughout the design process that can effectively support the building of theory. In design projects, theory is typically part of an initial secondary research phase but, often, fades into the background as the projects move into prototyping (Redström, 2017). Thus, in the studio-based design critique setting, design anthropologists might participate in building shared knowledge by introducing existing theoretical concepts and explanations during the later stages of the project. However, such an intervention requires that design anthropologists abandon some of the conventional modes of peer review that are common in the social sciences and, instead, create new hybrid cultures of critique. 
Furthermore, design anthropology presents an opportunity to move beyond the studio model and towards more distributed design practices (Forlano \& Mazé, forthcoming) enabled by digital tools. We draw on the National Science Foundation's definition of distributed collaboration from the "Beyond Being There" report, which emphasizes collaboration between "individuals whose members and resources may be dispersed geographically and institutionally, yet who function as a coherent unit through the use of cyberinfrastructure" (Cummings, Finholt, Foster, Kesselman, \& Lawrence, 2008, p. 1). According to the report, virtual organizations (VOs) include collaboratories, e-Science, distributed teams, virtual environments, and online communities. They often share resources such as tools, applications, data and computing. While there are a wide variety of models for VOs, the majority share the following characteristics: distributed across space and time; dynamic processes and, computationally enabled and enhanced. VOs include a wide range of fields and disciplines including scientific projects focusing on earthquake, cancer, energy, and physics research. In principle, VOs supported by digital tools are also possible in the humanities and social sciences as well as in the field of design - for example, The Humanities, Arts, Science, and Technology Advanced Collaboratory (HASTAC; http://www.hastac.org). However, the report states that "While communities will certainly adopt a new tool that advances their science, a tool may not be enough to motivate a complex, distributed collaboration unless the collaboration is absolutely necessary, as in the case of highenergy physics" (Cummings et al., 2008, p. 15).

However, despite the wide range of examples of distributed collaboration from other scientific disciplines, the report does not describe the role of critique and feedback or the ways in which the digital platforms support such engagements. For example, in the report, there were over 120 mentions of the term collaboration but no mentions of the term critique and only one mention of the word feedback (Cummings et al., 2008). As a result, we believe that design anthropology might draw on the merits of studio-based design critique in order to develop practices for distributed collaboration. These practices could also be used to support distributed collaboration in other disciplines.

In order to make these arguments, first, this paper will give an overview of literature on critique as well as illustrate the typical modes of critique within the design field. Second, this paper will draw on empirical examples from a range of design critique settings including educational settings and professional practice. Third, this paper will discuss the implications of these findings for the field of design anthropology in the development of distinct practices of critique. Finally, this paper will offer recommendations for the ways in which these emergent practices of critique might be embedded into digital platforms in order to move beyond the studio (Farías \& Wilkie, 2015) to support distributed 
collaboration in the field of design anthropology.

\section{Background}

This section aims to give an overview of the existing literature about critique and introduce common, established modes of feedback and assessment that are used in studio-based educational settings in the arts as well as the field of architecture and design. When done well, design critique can be used to motivate and focus students, move forward creative work, articulate the project in new ways, and discover


still exists a wide variation in terms of the structures, methods and outcomes of design critique. Often these differences are the result of distinct disciplinary orientations, specific studio cultures, and, even, individual personalities and preferences.

According to Dannels, Gaffney and Martin, a successful outcome of a critique is typically one where the project being discussed moves forward in some way, whether through helpful, pointed remarks or through a collaborative discussion among the student, facilitators, and other participants (2011). This is done in a variety of ways including the demonstration of design process, a thorough explanation of the object critiqued and design intent, narrative communication strategies, and "a careful management of critique interactions" (Dannels et al., 2011). They write that an unsuccessful outcome, on the other hand, prevents work from moving forward, usually due to the nature of the communication climate and communication instruction.

There are four types of design critique that take place in the studio at different stages of the project: desk critique (one-on-one meeting at the desk or in the studio while the project is in-progress); pinup critique (group meeting where students display work on a large wall or board); juries and reviews (mid-project or end of project formal presentations); and, open houses (end of project events with invited guests) (Dannels, 2005).

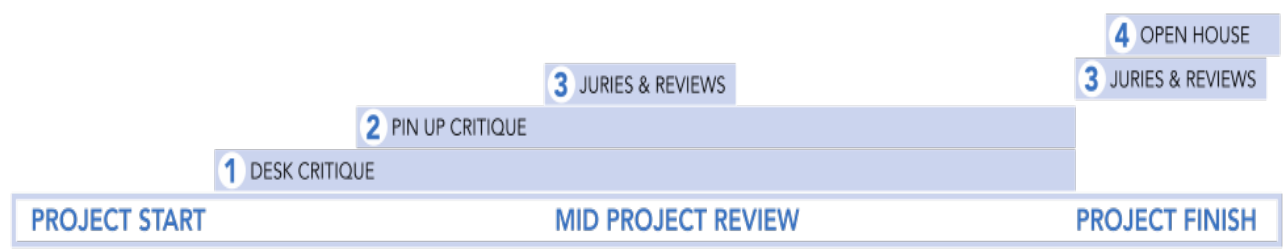

Figure 1. Four types of critique held throughout the design process

Some of these types of critique are informal and some are more formal; some are private and others are public (Oh et al., 2013). These 
four types of critiques can be used together in different sequences, typically alternating between desk critique and pin up critique before the more formal mid-project and end of project reviews.

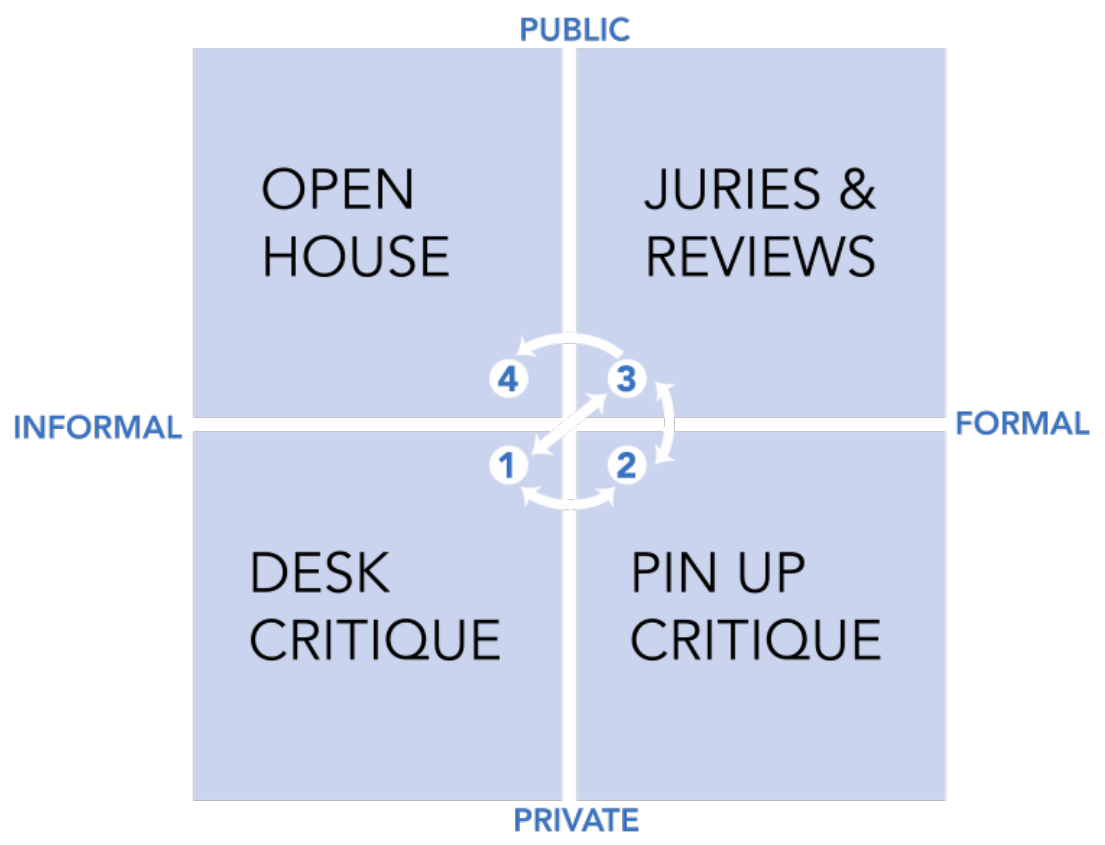

Figure 2. Relationship between the four types of critique

The critique session's success is shaped by the specific typology as well as by the participants, including facilitators and leaders (Oh et al.,

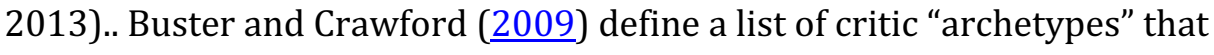
determine the nature of the critique and account for the varied methods: Connoisseurs, Judges, Evaluators, Specialists, Narcissists, Drill Sergeants, Unconditional Supporters, and Philosophers and Theorists. As critics, each is driven by different motives, which include aims as diverse as evaluating the work based on a specific set of objective criteria to evaluating the work based on its similarity or dissimilarity to the critic's own work. Having such a varied group of critics increases the chance of inconsistent experiences for participants.

The language of critique is another element critical to the success of a critique. From a student's perspective, the communicative climate is described as one of survival, cooperation, disclosure and detachment (Dannels et al., 2011). As one guide to critique says, "The first step to surviving the critique is to leave your ego at the door. All critiques test your ability to occupy the paradoxical position of being, at once, committed to your work and detached in critique" (Buster \& Crawford, 2009). Unfortunately, the communicative climate experienced by students is not always one that is conducive to learning. For example, 
according to choreographer Liz Lerman and John Borstel:

Critiques coming from those who had the privilege of holding forth - teachers, elders, critics — often felt like attacks, attacks imbued with a passion that seemed intimately connected with the aesthetic values of the beholder. (Even in the case of "positive criticism," the artwork sometimes functioned as a lightning rod for unspoken ideas, values, and assumptions.) Since "taking" the criticism quietly was the expected routine, we had no way of straightening out which values were being used as the standard (2003).

On the other hand, they acknowledge that feedback from peers was often overly positive and lacked usefulness. They write, "As a field, we needed a way to expose the previously unspoken values in criticism and to talk about work so that people could in fact have a dialogue and strengthen their own ability to solve the problems inherent in creative endeavors" (Lerman \& Borstel, 2003). Their Critical Response Process draws on the interactions, qualities (respect, trust, specificity, clarity, insight, integrity) and approaches that are typical of positive experiences with feedback and critique, those that motivate people to improve their projects. This emphasis on the values present within practices of design critique is important in understanding the different types of critique as well as the affordances of different styles, languages and settings (Flanagan, Howe, \& Nissenbaum, 2008; Flanagan \& Nissenbaum, 2014; Friedman \& Nissenbaum, 1996).

Similarly according to Dannels et al., students prefer feedback that is relevant, suggestive, balanced, engaged, considerate and consistent (2011). Fleming (1998) describes a continuum of language used during studio critiques that perform different functions based on the current state of the design process. The majority of the language used serves to establish the object being critiqued while providing the opportunity for the critic(s) to shape the eventual outcome. Fleming calls this "midproject, designer-to-designer talk." In this context, Oak (2011) applies Symbolic Interactionism and Conversation Analysis to studio critique conversations to determine the nature of discourse about the objects presented and the process of how new objects emerge from these discussions.

Following graduation from studio-based programs, professionals continue to use these modes of critique within their organizations, including in architecture firms, design consultancies or fine arts collaboratives. Critique in these contexts can be challenging because it is difficult to incorporate professionals with a wide variety of critique styles, formats and tones from diverse disciplines, institutions and educational settings. As a result, there is either tension between different traditions or a mandate from the organization that determines the structure and 
method of critique. While there are variations in the elements of a successful critique, there are also opportunities for organizations to shape these outcomes. Critique is a valuable practice and has been shown to be an important part of the traditions, rituals and values of the institutions where they are practiced (Dannels, 2005).

In professional settings, design critique is promoted as a project tool, and, as a result, there is discussion in mainstream media about the best practices of design critique and the reasons for using it. For example, the design consultancy Continuum refers to their own view of critique as an important part of a culture of "deliberative discourse," emphasizing consensus, participation and collaboration including aspects such as flattening group hierarchy, discussing the reasons one would say no to another's idea, embracing diverse perspectives, focusing on a common goal, and keeping it fun (Sobol, 2012). These deliberative, participatory and collaborative qualities can also be found in the history of participatory design and codesign (Sanders, 2002; Sanders \& Stappers, 2008; Schuler \& Namioka, 1993).

Embedded within this perspective on participation and collaboration is the value of critique, dissensus, tensions and frictions (DiSalvo, 2012; Hillgren, Seravalli, \& Emilson, 2011; Mouffe, 2003). Rooksby and Ikeya (2012) discuss collaboration in the context of design by looking at pairs of developers designing traffic simulation software. In this case, the factors that produced successful collaboration included listening to each other, maintaining a shared focus, being open to each other's ideas, and seeking agreement and acknowledging disagreement, aligning with the elements of design critique. Similarly, in an article about working with virtual, multi-ethnic and global project teams, Neeley discusses the importance of creating certain types of moments such as forcing disagreements and stressing differences in order to facilitate group work (2012). These projects can often go a long time without bringing disagreements to light since participants do not have the opportunity to discuss issues in a face-to-face environment. As a result, it is important to give participants opportunities to disagree with one another and to offer critique and feedback (Neeley, 2012).

While the practices around critique are modeled and learned in studio-based educational settings, there have been some recent publications that attempt to formalize the process for professional practice. For example, in Discussing Design: Improving Communication \& Collaboration Through Critique (2015), Connor and Irizarry describe the reasoning, process, and role of critique as a form of collaboration in everyday work. While the main premise of the book supports the mindset and foundation of critique within organizations, they also give examples of digital tools that support virtual and remote collaboration. However, these tools are not necessarily paired with the types of critique that they support and no single tool supports all facets of critique in collaboration. 


\section{Methodology}

The research presented in this paper is based on a two-year, qualitative study of design collaboration that ran from September 2010 to August 2012 in which ethnographic observation (Glaser, 1992; Marcus, 1995; Strauss, 1987) and open-ended interviews were conducted with designers and design educators in four countries (United States, Canada, Spain and Australia). This paper focuses primarily on the first year of the research in which 26 one-hour interviews were conducted with designers from a variety of fields including architects, graphic designers, product designers, design strategists, service designers, industrial designers and interaction designers in the United States and the majority of them were based in New York. However, several of these designers were based in other cities including Pasadena, CA, Pittsburgh, PA, Savannah, GA, Milan, Italy and Tel Aviv, Israel. Approximately two-thirds of the designers were practicing professionals and the remaining one-third were educators based at an art, design or architecture school. Exactly 13 participants were male and 13 were female. Most of the designers were in their early to mid-40s, but one was a recent graduate from a design school. Nineteen interviews were conducted in person and seven were conducted via Skype. Interviewees were recruited via their public participation in design-related events in New York and/or their affiliation with a design network hosted by the Parsons of Design at the New School.

The focus of the research was to better understand the core activities that comprise design collaboration as this relates to face-to-face and distributed forms of interaction as well as the use of networked collaboration tools. Specifically, designers were asked to describe their ongoing collaborative projects, their use of particular design methods and processes and their use of technology and social media. All interviews were audio-recorded, documented with notes and photos, and transcribed. Following the completion of the interviews and preliminary coding of three transcripts, a comprehensive coding scheme was developed to identify emerging themes.

In addition to using discourse analysis in order to code the data and identify themes, the Mandala Browser ${ }^{1}$, a rich-prospect interface that allows users to explore text-based data visually by searching and extracting lines of text from files based on keywords, was also used. The browser visually represents the frequency and connection between keywords within the uploaded text files. In this case, the interview transcripts were loaded into the browser, and the keywords 'critique', 'collaboration', 'feedback' and 'evaluation' used to identify passages in the interviews that referred to those specific terms. By extracting these passages from the browser, it was possible to verify that the discourse analysis had correctly identified the most relevant quotes as well as to

\footnotetext{
${ }^{1}$ See mandala.humviz.org/. Accessed on January 28, 2018.
} 
integrate additional quotes that may have been overlooked and ignored during the discourse analysis. Finally, the browser creates a brightly colored visual mapping that is helpful for understanding the prevalence and relationship between keywords in the interview data (see below).

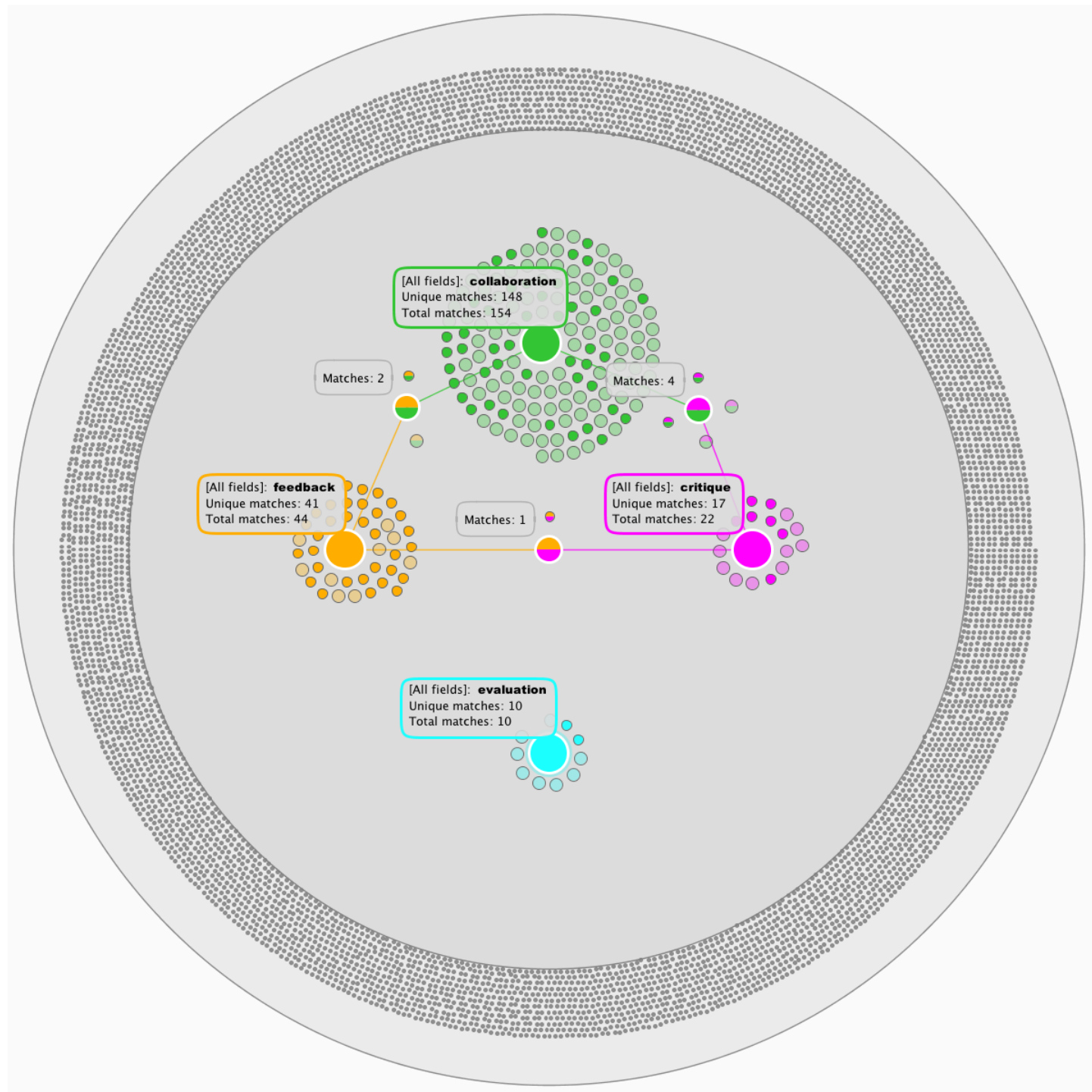

Figure 3. The result of the interview data analysis with the Mandala Browser

\section{Findings}

In the following section, we present examples of the role of critique as a form of collaboration in a variety of educational and professional contexts. First, we discuss the tradition of critique in art studios and design workshop settings. Next, we present examples of critique from professional design practices. These examples illustrate the role of critique as a face-to-face practice in both formal and informal settings. 


\section{Design Critique in Studio-Based Educational Settings}

Our first example is based on the experience of a New York City-based graphic designer, Emma, who attended Cooper Union and subsequently founded her own design studio that specializes in exhibition design. She describes the critiques among students in a class as "pretty harsh and intense" for an 18-year old art student. Another design strategist, Alexa, with her own consultancy, echoes this sentiment saying, "In the design world, we're often used to this idea of a critique. You get up there and everything gets torn to shreds."

While the critiques were difficult at first, they were transformative in that they allowed her to view her work from alternative perspectives and introduced her to different ideas. She says, "If you've got a reason and you've got a conceptual explanation...then it puts you in a stronger place to talk about your work." In this statement, Emma articulates the difference between a mere whim and a rationale that is based on iterative trial and error of many different approaches. She explains that this is an important part of educating a client about the design process and the decisions that are being made at any given time.

In Emma's experience, "critique is collaboration." She goes on to say that it is a:

nascent way of feeling more comfortable with somebody saying something negative, or that they actually make a more in depth, more nuanced critique of your work, and they get involved in it enough that they could actually almost take over the project and run with it and develop it in a different way...[there was] a level of involvement and comfort with the critique that developed, that seems to me that it made collaboration easier.

According to Emma, in an educational context, one of the most important aspects of enabling a productive culture of critique and collaboration is access to physical studio space and desk space for informal critiques. For example, she says:

I would even be putting my printmaking and stuff out on the desk, and people would be pinning stuff up, and people would be asking opinions and weighing in on it, completely outside of any classroom critique. You knew what everybody else was doing. There was no hiding anything. Not that this happened a lot, but if somebody was struggling to put something together for a deadline, you could ask somebody else to help you. You weren't alone at night at 11PM not knowing how you were going to do it.

The highly visual nature of art and design work is a factor that allows it to be displayed publicly, which attracts people to it and enables them to provide valuable feedback to designers. This supports the findings of an earlier study of design work, which showed that web 
designers working in public settings such as cafes were able to gather useful feedback from future audiences by displaying their work visually (Forlano, 2008, 2009).

Another example of the importance of critique in collaboration is from an architectural school context. In this case, in the first part of the semester, the professor, Jane, required students to design specific building elements (for example, doors, windows, roofs and cooling/heating systems) but prohibited them from using these elements in the second half of the semester. Instead, the graduate students had to "respond to people's critique of that element in a very open-minded way to transform it according to the desires of other students...This question of designing something that somebody else uses later on is really radically different," said Jane.

Participation in a critique of one's work implies a kind of openness and transparency. However, in the field of professional architecture practice, large firms in New York are hesitant to make their work public until the later stages in a project. According to one architect, Mason, who runs her own architecture studio:

The culture is very much, "I'm going to hide this drawing until we publicize things and I know that it's my project" because people are very concerned about the look of a project being stolen...you don't want to talk about the deal until the deal is done and then you want to talk about it to everybody.

She goes on to say that, in architecture, there is a fear that if a designer goes public with a drawing or rendering that something could be manipulated. Mason states, "The manipulation that is feared is not even so much that someone will steal an idea; it's more that someone will critique an idea," laughing at the irony of this fact given the importance of critique in design training and practice. For example, according to Mason, in the case of the plans for the Atlantic Yards stadium in Brooklyn, Amanda Burdan, the director of the New York City Department of City Planning, had a city planner leak a rendering to the New York Times in order to expose the project to public critique and pressure the developer to change it.

In the case of graduate design programs, and, in particular, those that enroll a variety of students with design and non-design backgrounds, there is a need to establish a baseline of knowledge related to the purpose and nature of critique as well as to create ground rules for collaboration. For example, according to Rachel, the director of a new design program in New York, students expressed concerns and doubts about themselves, their colleagues and teammates and the overall curriculum. She came to the conclusion that "The curriculum was not preparing them to do something that they were being asked to do." As a result, the program circulated written guidelines about how to do critiques and ways to 
approach critiques and integrated this into the curriculum in a more formal manner. For example, the guidelines might be as simple as 'raise your hand if you have feedback about the idea that I presented' or a more elaborate plan for how a four-person team might work together. Rachel offered the following guidelines for critique and multidisciplinary collaboration:

1. The idea is not the deliverable...[it] is a throw away. Focus on the idea, but know that it [can] be discarded.

2. Deliver appropriate feedback about the work, but know that you're working towards a larger goal, which is the group project and the group consensus.

3. Stay open to others. Understanding that each person has something to contribute.

4. [Know] that at any point you may need to take the lead to make your idea heard...and to work harder to see it come to bear.

At another design school across the country, a sustainable design professor, Sam, emphasizes the importance of self-critique in terms of "busting...and challenging one's own assumptions," as integral to the design process.

At the Institute of Design at Illinois Institute of Technology, design critique is incorporated into the Foundation classes, particularly in the communication design and product design courses. For students who enter the graduate program without a background in formal design training, they go through a rigorous two semester foundational program that teaches communication design, product design, multi-media and digital design, photography, and history of design. All four forms of design critique discussed in the previous section are used during class including desk critique, pin-up critique, juries/reviews and open houses.

Although design critique is practiced in these formal and informal situations throughout the courses, there are differences in style, approach, climate, environment and language depending on the faculty member. Each faculty member has a different style of facilitating and participating in the critique, which produces a different experience within the class and in the type of work produced. Both the methods as well as the physical space used for critique also differ across faculty members. For instance, pinup critiques in the communication design class take place in a classroom with a projector, whereas pinup critiques in the product design class take place in an open studio.

In an educational setting, there is an imposed hierarchy because the faculty member plays the role of guiding and facilitating the critique at various stages of individual and group projects. In this case, the faculty 
member, peers and invited design professionals provide important feedback to help students improve the work. However, as students gain familiarity with the practices of design critique, they are also able to provide feedback to each other as peers outside of the classroom on individual and group projects, which removes the hierarchy associated with the faculty-student critiques. A typical team might consist of a group of students with diverse age, gender, ethnicities, countries of origin and academic backgrounds such as a graphic designer in her late $20 \mathrm{~s}$, a musician-turned-designer in his mid-30s, a business consultant in his early 40s, and a former mechanical engineer from the foundation program in his early 20s. Within this context, student teams employ informal design critique methods including desk critiques and pin-up critiques in order to collaborate effectively on projects. For example, when using a desk critique a student might ask their team members for feedback on part of their work and when using a pin-up critique they might display the work they have done individually to the rest of the group and discuss it. As a team-based project, students are not judging the work as individuals, but as a part of the whole. In addition to peer feedback within teams, students will also share their work with other teams and receive feedback. Finally, faculty members will meet with teams individually. Formal critique methods are used primarily during mid-term reviews and final presentations sometimes with an outside organization or sponsor.

\section{Design Critique in Professional Practice}

Critique is equally important in educational settings as it is in the world of professional design practice but it may be applied in different ways depending on the individual firm. For example, rather than adopt the harsh critique common in the design school model, Alexa's design consultancy uses concepts of divergence and convergence during brainstorming (Osborn, 1953). Specifically, while divergent thinking stresses the generation of as many different ideas as possible, convergent thinking focuses on narrowing down the range of options.

For Jeremy, an architect that heads an exhibition design firm, the design process follows a "creation, evaluation, and curation" approach. He states that designers should be open to improvements in their ideas from their colleagues as well as from dialogues with their clients. In this way, the designer is both "a generator and/or a consolidator of different ideas." In particular, the multi-disciplinarity of Jeremy's studio allows for an open, collaborative environment where designers can get feedback from a variety of design practitioners including 3D designers, graphic designers, motion designers, writers, researchers, animators, interaction designers, front-end coders, and back-end developers.

Rather than showing clients a single design solution, which sends 
the message that the designer controls everything, Jeremy's firm works collaboratively with their clients by showing them a range of different approaches to a specific design and asking for feedback:

Because we want them to feel empowered, and to understand our thinking behind choosing a certain approach. Furthermore, we want them to criticize, and deconstruct, and improve our design approaches...we're constantly showing them a wide variety of designs and making our preference very clear. But always showing them the other options and getting their input...And actually, more and more of what we do is not even tell them our preference. We just say, "We're not even going to try and sway you in any direction. We're just going to show you here's option A, $\mathrm{B}$, and C; and you interpret for yourself,"...We want their frank unadulterated opinion in what's working and what's not working and that's the value of the client is that they'll see it at such a different angle.

In fact, Jeremy's firm does not work with clients that are unable or uninterested in participating in the design process either due to a lack of interest or a lack of knowledge. While Jeremy insists that his team integrate his design philosophy and specific comments into their design approaches, he does not want to restrict their creativity. He tells them:

If and when you ever think that you have a better idea than me, I want to see that idea. I want you to actively develop parallel ideas that can contradict, or undercut any of my approaches...Even down to the last day of final design. If you think it's better, I want to know about why you think it's better, and I want you to prove to me that it's better. I want you to prove not just to me that it's better, I want you to prove to the whole studio...Nothing would make me happier than to have an entire studio filled with incredibly talented, over achieving people, who are coming up with such amazing and incredible ideas, that they eclipse my own vision.

Similar to the importance of physical studio space and desk space in a pedagogical setting, design firms emphasize the importance of their mock-up rooms as well as of prototypes and mock-ups more generally. In fact, Jeremy's studio creates mock-ups during the design development process in order to pitch their work to potential clients. He argues that mock-ups are important, "For all clients, it helps really focus them, and that's critical. It draws their attention, and it give them something to rally around, to understand, to approve, to criticize...". According to Jeremy, the mock-ups become:

a lightning rod for their dissatisfaction, which is really helpful. When we invite clients to look at our mock-ups, we don't invite them to sign off on things. We want them to criticize it. We want 
them to improve it. We want to basically dig out any and all of their negative feedback at that moment, because it's much better then than when we launch. Once it's built, it's done. You don't have an opportunity to change it.

The mock-ups enable the design team to question their assumptions, determine whether what they set out to do is actually what they want to do and evaluate whether their ultimate solution meets their design goals. By bringing a variety of different stakeholders into the studio and inviting them to evaluate, refine and criticize the mock-up, it is possible to synchronize the design approach with the client's actual needs and wants. It is particularly important to get feedback from the client as early as possible in the design process in order to align the approach with the client's goals. Often, Jeremy's firm will build a mock-up in their studio for the client to see in order to avoid problems when the actual exhibition is installed and launched in a public space. He says:

we built a completely verbatim mock-up, down to the inch, with all the hardware, all the graphics. It was built out of plywood on the outside, but all the interaction design and technology was exactly the same...we want all the criticism, but we can't have it when we go to [the site of the installation] because it's too late then.

Jeremy likens design collaboration to the work of sitcom script and comedy writers sketching out ideas; it is "a group of people pinning up 30 different approaches onto the wall and discussing which ones work or don't work. It's that group of people throwing out different ideas and just hammering away, trying to come up with a bunch of different approaches...it's basically people in the same space together throwing around ideas."

He emphasizes the importance of physical space and says that virtual collaboration is difficult in design work because it is difficult to get to know people and understand what they are thinking by phone or Skype because these interfaces tend to reinforce social norms of politeness. According to Jeremy, "You really need to know the people and trust them on a deeper level than just hearing their voice...when you're collaborating with people, you shouldn't be polite, you should be energetic, and sarcastic. You should have fun, but being restrained and polite is not helpful." Similarly, the graphic designer, Emma, says that 7080 percent of their work is locally based in New York because it is still difficult to coordinate design work remotely. For example, for a Spanish client, they had problems providing feedback and having a dialog about photographs of an exhibition installation because it was difficult to understand what looks good on a wall without accurate photographs. For another project, Emma used mock-ups of what things would look like in place in order to get feedback saying, "it's easier to talk about it when it 
looks, for all intents and purposes, real, and get feedback from them that way."

According to a product designer at a large, global design consultancy, Thomas, a two to five-person design team is common but a three-person team is ideal:

Three is a magic number [in Western Culture]. Like there's Father, Son and Holy Ghost. There's three little pigs. There's Three Stooges. There's three strikes and you're out. But, in terms of the group dynamic is there's kind of point, counterpoint and alternate idea. So you can get a sort of triangulated discussion...it often injects just enough of a new idea to keep things fresh.

While discussions between two people can stagnate quickly, a third person is critical to move the ideas forward. In addition, it is important to bring in advisors at different points to provide feedback.

\section{Discussion}

Design anthropology as a field exists at the intersection of differing cultures around peer review, feedback and critique. Yet, the field does not yet have an established, codified practice of critique that might allow for it to build foundational theories. Specifically, while anthropology incorporates norms that are common in the social sciences, which emphasize long-term individual projects (Choy et al., 2009), design reinforces shorter-term, collaborative projects. In the social sciences, critique typically happens through blind peer review processes that are intended to provide an assessment of the work, offer feedback and, ultimately, decide whether a particular article is worthy of publication. In design, critique typically happens through a wide variety of formats in the studio. While an in depth comparison of the values and norms associated with critique across different fields is beyond the scope of this article, our findings provide a deeper understanding of studio-based design critique as a basis for the emergent field of design anthropology.

A deeper analysis of our findings suggests three broad clusters of values present within design critique: openness, multiplicity and collaboration. First, our informants emphasized the importance of openness and related concepts such as transparency, awareness, sharing. Second, our informants reinforced the value of multiplicity including multi-disciplinarity as well as multiple solutions, approaches and improvements. The focus on multiplicity along with contradictions and divergent ideas resists hierarchical control of knowledge and, rather, emphasizes that each person has something to contribute to improving the conversation around the work in line with theory around codesign and participatory design. Third, our informants emphasized that critique is a process of collaboration, which requires involvement and 
participation. Here, the affective qualities of trust, comfort, energy and, even, sarcasm are necessary to maintain an atmosphere conducive to supporting the development of the work. Rather than leaving a critique session feeling disillusioned or disappointed, designers seek to empower participants (in part due to their own negative experiences with harsh critiques during their educations in art, design and architecture schools).

Based on this analysis, we argue that critique can be understood as a generous and generative collaborative practice in ways that differ substantially from the norms and values that are common in the social sciences and, specifically, in anthropology. In order for the field of design anthropology to begin to create new models for building theory, it must first develop useful and effective norms and cultures around the practice of critique. These emergent norms should build on studio-based design critique and traditional models of peer review in the social sciences as well as more nascent and experimental practices that are taking hold in the social sciences. For example, the Journal of Peer Production ${ }^{2}$ and Ada: A Journal of Gender, New Media, and Technology 3 are two open access journals that have instituted alternatives to traditional blind peer review processes. The Journal of Peer Production builds on an argument by Whitworth and Friedman (2009a, 2009b) that suggests that the norms of academic publishing are risk-averse and stifle the creation of new ideas. Instead, the journal adopts their proposed alternative evaluation system, which emphasizes community involvement, multiple modes of evaluation as well as informal and formal evaluations. As a result of using this model, the journal publishes the reviews and a 50-word commendation from the reviewers along with the final article. This process preserves the doubleblind nature of the review process, which aims to provide "frank and fearless" feedback but offers the options of making the reviewers names public once the article has been accepted. The publication of the reviews reinforces the norm that the reviewers should "use a respectful tone" regarding the article that they are reviewing. Similarly, $A d a$ 's process is stated as: "Contributions are reviewed by Fembot Collective members using a multi-level open peer review process." In this case, reviews are not anonymous but, rather, come from an identified member of the Fembot Collective. These two examples illustrate that there are emergent practices within the social sciences that seek to create new norms around openness, multiplicity and collaboration, which align with the characteristics that we observed in our study of studio-based design critique.

Finally, our data illustrate the ways in which digital tools are typically insufficient to support the values and norms associated with studio-based design critique because they tend to favor politeness,

\footnotetext{
${ }^{2}$ See http://peerproduction.net/peer-review/process/. Accessed on January 29, 2018.

${ }^{3}$ See http://adanewmedia.org/about/. Accessed on January 29, 2018.
} 
reservation and agreement rather than frank, unrestrained conversation that is focused on exposing contradictions and disagreements, thereby making way for multiple possibilities. Furthermore, while there has been substantial research on virtual organizations and distributed collaboration, there has been much less attention to designing digital platforms to support dissensus, tension and friction. Our findings suggest that it would be useful to consider these values in the design of platforms intended to support collaboration across distance.

\section{Conclusion}

This study illustrates the importance of practices around design critique as forms of collaboration based on examples from studio-based educational settings and professional practice within architecture studios and design consultancies. A better understanding of these practices is vital for the emergent field of design anthropology because the norms around peer review, feedback and critique differ substantially across the fields of design and anthropology. Specifically, for design anthropology to succeed in building theory from practice-based design methods, it is necessary to find ways to intervene and interject theoretical concepts into studio-based cultures of critique across the entire design process (rather than merely at the beginning as is common in many projects).

At the same time, in order to expand the field, design anthropology has the opportunity to move beyond the confines of the studio and towards the building of collaborative global network of scholars and practitioners as are typical in other scientific disciplines through the use of digital platforms. However, our research shows that there are still significant barriers to creating distributed, remote and virtual practices that maintain the values and cultures of the design studio. And, while the availability of online platforms is growing, there are still no tools that support the different styles, approaches, languages and values of critique that are common in the studio with a specific focus on openness, multiplicity and collaboration.

\section{Acknowledgements}

This research was supported by the US National Science Foundation's Division of Advanced Cyber Infrastructure for a project on "Design Collaborations for Socio-technical Systems” (Award \#1025498). 


\section{References}

Agre, Philip. (1997). Toward a critical technical practice: Lessons learned in trying to reform AI. In Bridging the Great Divide: Social Science, Technical Systems, and Cooperative Work, Mahwah, NJ: Erlbaum, 131-157. Buchanan, Richard. (2001). Design research and the new learning. Design Issues, 17(4), 3-23. https://doi.org/10.1162/07479360152681056

Buster, Kendall, \& Crawford, Paula. (2009). The Critique Handbook: The Art Students' Sourcebook and Survival Guide. Boston, MA: Prentice Hall. Choy, Timothy K, Faier, Lieba, Hathaway, Michael J, Inoue, Miyako, Satsuka, Shiho, \& Tsing, Anna. (2009). A new form of collaboration in cultural anthropology: Matsutake worlds. American Ethnologist, 36(2), 380-403. https://doi.org/10.1111/j.1548-1425.2009.01141.x

Connor, Adam, \& Irizarry, Aaron. (2015). Discussing Design: Improving Communication and Collaboration Through Critique. Sebastopol, CA: O'Reilly Media.

Cummings, Jonathon, Finholt, Thomas, Foster, Ian, Kesselman, Carl, \& Lawrence, Katherine A. (2008). Beyond being there: A blueprint for advancing the design, development, and evaluation of virtual organizations. Washington, D.C.: National Science Foundation.

Dannels, Deanna P. (2005). Performing tribal rituals: A genre analysis of "crits" in design studios. Communication Education, 54(2), 136-160. https://doi.org/10.1080/03634520500213165

Dannels, Deanna P., Gaffney, Amy L. Housley, \& Martin, Kelly Norris. (2011). Students' talk about the climate of feedback interventions in the critique. Communication Education, Vol 60(Issue 1), pp.95-114. https://doi.org/10.1080/03634523.2010.487111

DiSalvo, Carl. (2012). Adversarial design. Cambridge, MA: MIT Press.

Farías, I. , \& Wilkie, A. (Eds.). (2015). Studio Studies: Operations, Topologies \& Displacements. New York: Routledge.

Flanagan, Mary, Howe, Daniel, \& Nissenbaum, Helen. (2008). Embodying values in technology: Theory and practice. Information technology and moral philosophy, 322-353.

Flanagan, Mary, \& Nissenbaum, Helen. (2014). Values at Play in Digital Games. Cambridge, MA: MIT Press.

Fleming, David. (1998). Design Talk: Constructing the Object in Studio Conversations. Design Issues, Vol 14(No 2), pp. 41-62.

https://doi.org/10.2307/1511850

Forlano, Laura. (2008). When Code Meets Place: Collaboration and Innovation at WiFi Hotspots. (Ph.D.), Columbia University, New York.

Forlano, Laura. (2009). WiFi Geographies: When Code Meets Place. The 
Information Society, 25, 1-9.

https://doi.org/10.1080/01972240903213076

Forlano, Laura, \& Mazé, Ramia. (forthcoming). Demonstrating and Anticipating in Distributed Design Practices. Demonstrations.

Friedman, Batya, \& Nissenbaum, Helen. (1996). Bias in computer systems. ACM Transactions on Information Systems (TOIS), 14(3), 330-347. https://doi.org/10.1145/230538.230561

Glaser, B. (1992). Basics of grounded theory analysis. Mill Valley, CA: Sociology Press.

Gunn, Wendy, Otto, Ton, \& Smith, Rachel Charlotte. (2013). Design anthropology: theory and practice. New York: Bloombsbury.

Hillgren, Per-Anders, Seravalli, Anna, \& Emilson, Anders. (2011). Prototyping and infrastructuring in design for social innovation. CoDesign, 7(3-4), 169-183. https://doi.org/10.1080/15710882.2011.630474

Lerman, Liz, \& Borstel, John. (2003). Critical Response Process: a method for getting useful feedback on anything you make, from dance to dessert. Takoma Park, MD: Dance Exchange, Inc.

Marcus, George E. (1995). Ethnography in/of the World System: The Emergence of Multi-Sited Ethnography. Annual Review of Anthropology, 24, 95-117. https://doi.org/10.1146/annurev.an.24.100195.000523

Mouffe, Chantal. (2003). Pluralism, dissensus and democratic citizenship. II Seminário internacional educação intercultural, gênero e movimentos sociais. Identidade, diferença, mediações, 1-10.

Neeley, Tsedal. (2012). Global Team Leaders Must Deliberately Create 'Moments' Retrieved from http://blogs.hbr.org/cs/2012/03/global team leaders must delib.html

Oak, Arlene. (2011). What can talk tell us about design? Analyzing conversation to understand practice. Design Studies, 32(3), 211-234. https://doi.org/10.1016/j.destud.2010.11.003

Oh, Y., et al.. (2013). A theoretical framework of design critiquing in architecture studios. Design Studies, 34(3), 302-325.

https://doi.org/10.1016/i.destud.2012.08.004

Osborn, Alex (1953). Applied Imagination: Principles and Procedures of Creative Problem Solving. New York, NY: Charles Schribner's Sons.

Pickering, Andrew. (1995). The Mangle of Practice: Time, Agency, and Science. Chicago: University of Chicago. https://doi.org/10.7208/chicago/9780226668253.001.0001

Ratto, Matt. (2011). Critical making: Conceptual and material studies in technology and social life. The Information Society, 27(4), 252-260. https://doi.org/10.1080/01972243.2011.583819 
Reckwitz, Andreas. (2002). Toward a Theory of Social Practices: A Development in Culturalist Theorizing. European journal of social theory, 5(2), 243-263. https://doi.org/10.1177/13684310222225432

Redström, Johan. (2017). Making Design Theory. Cambridge, MA: MIT Press.

Rooksby, John, \& Ikeya, Nozomi. (2012). Collaboration in Formative Design: Working Together at a Whiteboard. IEEE Software, pp. 56-60. https://doi.org/10.1109/MS.2011.123

Sanders, Elizabeth B-N. (2002). From user-centered to participatory design approaches. Design and the social sciences: Making connections, 18. https://doi.org/10.1080/15710880701875068

Sanders, Elizabeth B. -N., \& Stappers, Pieter Jan. (2008). Co-creation and the new landscapes of design. CoDesign, 4(1), 5-18.

Schön, D.A. (1983). The Reflective Practitioner: How Professionals Think in Action. New York: Basic Books.

Schuler, Douglas, \& Namioka, Aki. (1993). Participatory design : principles and practices. Hillsdale, N.J.: L. Erlbaum Associates.

Shove, Elizabeth, Pantzar, Mika, \& Watson, Matt. (2012). The dynamics of social practice: everyday life and how it changes: Sage Publications.

Sobol, Daniel. (2012). Innovation is about arguing, not brainstorming. Here's how to argue productively. Retrieved from http://www.fastcodesign.com/1669329/dont-brainstorm-argue

Soep, Elisabeth. (2005). Where art meets assessment. Phi Delta Kappan, Vol 87(No 1), 38-63. https://doi.org/10.1177/003172170508700109

Strauss, A. . (1987). Qualitative analysis for social scientists. . Cambridge, England: Cambridge University Press.

Wakkary, Ron, Odom, William, Hauser, Sabrina, Hertz, Garnet, \& Lin, Henry. (2015). Material speculation: Actual artifacts for critical inquiry. Paper presented at the Proceedings of The Fifth Decennial Aarhus Conference on Critical Alternatives.

Whitworth, Brian, \& Friedman, Rob. (2009a). Reinventing academic publishing online. Part I: Rigor, relevance and practice. First Monday, 14(8). https://doi.org/10.5210/fm.v14i8.2609

Whitworth, Brian, \& Friedman, Rob. (2009b). Reinventing academic publishing online. Part II: A socio-technical vision. First Monday, 14(9). https://doi.org/10.5210/fm.v14i9.2642

Zimmerman, John, Forlizzi, Jodi, \& Evenson, Shelley. (2007). Research through design as a method for interaction design research in HCI. Paper presented at the Proceedings of the SIGCHI conference on Human factors in computing systems. https://doi.org/10.1145/1240624.1240704 
Laura Forlano is Associate Professor of Design at the Institute of Design and Affiliated Faculty in the College of Architecture at Illinois Institute of Technology where she is Director of the Critical Futures Lab. Her research is on the intersection between design and technology around themes including ethics, materialities and futures around topics such as smart cities, distributed work, computational fashion and medical technologies. Forlano's recent publications include "Posthumanism and Design," (She Ji) "Data Rituals in Intimate Infrastructures" (Catalyst) and "Demonstrating and Anticipating in Distributed Design Practices" (Demonstrations) and she has published in journals including Design Issues, Fibreculture, First Monday, Journal of Urban Technology and Digital Culture \& Society. Forlano is co-editor with Marcus Foth, Christine Satchell and Martin Gibbs of From Social Butterfly to Engaged Citizen (MIT Press 2011). She has published chapters for books including editor Mark Shepard's Sentient City (MIT Press 2011). She received her Ph.D. in communications from Columbia University.

Stephanie Smith is an Adjunct Faculty member and the Director of Corporate and Community Partner Engagement for the Institute of Design at Illinois Institute of Technology. She has also played roles as an experience design manager in the healthcare industry with experience in design-led innovation consulting and design research spanning multiple industries including heavy manufacturing, financial services and products, insurance, and consumer packaged goods. She is a frequent speaker on the application of design and innovation in business. Prior to working in design, Stephanie worked in the music industry in promotion, sales and marketing, artist and repertoire, and as a practicing musician. She also co-founded a technology startup in the meetings industry. She received her M.Des. at the Institute of Design and M.B.A. at the Stuart School of Business, both at Illinois Institute of Technology. 